\title{
Covid-19 and Vitamin D Deficiency: A Scientometric Assessment of Global Publications during 2020-21
}

\author{
Devi Dayal ${ }^{1, *}$, BM Gupta $^{2}$, M Surulinathi ${ }^{3}$, Pamali Mahasweta Nanda ${ }^{1}$ \\ 'Postgraduate Institute of Medical Education and Research, Department of Pediatrics, Chandigarh, INDIA. \\ 2Formerly with CSIR-National Institute of Science, Technology and Development Studies, New Delhi, INDIA. \\ ${ }^{3}$ Bharathidasan University, Department of LIS, Tiruchirappalli, Tamil Nadu, INDIA.
}

\begin{abstract}
Background: Several studies have examined Vitamin D deficiency (VDD) and the effects of vitamin $D$ therapy in patients with coronavirus disease 2019 (Covid-19). However, a bibliometric assessment of research output on VDD in relation to Covid-19 is unavailable. Materials and Methods: We searched Elsevier's Scopus database for publications on VDD in Covid-19 using a defined search strategy. Data pertaining to the growth of publications, citation metrics, the most active countries, institutions, authors, journals, and the most cited articles, were analyzed using appropriate bibliometric tools. Mapping of keywords was done to identify the research trends. Results: Of 435 global publications on VDD in Covid-19, $187(42.9 \%)$ were original articles. The total and average citations per paper (CPP) were 5664 and 13.0, respectively. Eighty-eight (20.2\%) publications were funded; the National Institute of Health, USA, was the leading funding agency $(n=18)$. Seventy-four countries participated in research on this theme; the USA and Italy with $18.3 \%$ and $16.5 \%$ led in productivity, whereas Ireland and the USA were the most impactful. The most dominant research topic was "Risk Factors" with 29.6\% share, followed by "Epidemiology" (27.3\%), "Complications" (26.4\%), "Clinical studies" (24.8\%), and "Pathophysiology" (17.2\%), only $14.0 \%$ studies were on "Treatment." The research patient populations were "Adults", "Aged," and "Middle-Aged," with 24.1\%, 21.6\%, and 17.7\% share, respectively; only $6.4 \%$ studies involved children. The organizations and authors numbered 254 and 383, respectively; Trinity College, Dublin, Ireland, and Harvard Medical School, USA, were the most productive, whereas
\end{abstract}

St. James's Hospital, Ireland, and University Hospital Brigham, UK were the most impactful. Belgium's Delanghe and Ireland's Kenny were the top productive authors, and Grant (USA) and Laird (Ireland) were the most influential. Journal of Medical Virology and Endocrine lead productivity while Aging Clinical and Experimental Research and Diabetes and Metabolic Syndrome: Clinical Research and Review lead in impact. Conclusion: The research on VDD in relation to Covid-19 has primarily been conducted in high-income countries, with the USA, Italy, and UK accounting for almost $50 \%$ of total publication output. The research gaps appear to be treatmentrelated aspects and VDD in children with Covid-19. Our assessment of the current status of research on VDD in Covid-19 may help the research community and policy-makers to prioritize research needs in this field.

Key words: Coronavirus disease 2019, Vitamin D Deficiency, Bibliometrics, Research impact, Scientometrics, Children.

Correspondence

Prof. Devi Dayal,

Endocrinology and Diabetes Unit, Department of Pediatrics, Advanced Pediatrics Center, Postgraduate Institute of Medical Education and Research, Chandigarh-160012, INDIA.

Email id: drdevidayal@gmail.com

DOI: 10.5530/jyp.2021.13s.77

\section{INTRODUCTION}

The world is currently witnessing an unprecedented crisis of the Covid-19 pandemic. The pandemic has caused severe devastation globally and the crumbling of health infrastructures in developing countries. ${ }^{1,2}$ The Covid-19 is associated with significant morbidity and mortality due to its severe effects on the respiratory system and other organ systems, especially in those with comorbid conditions. ${ }^{3,4}$ In addition to comorbidities, several other risk factors, such as female sex, lack of Covid-19 appropriate behavior, large households, BCG vaccination, etc., are presumed to play a role in the Covid-19-related morbidity and mortality. ${ }^{5-8}$ One such risk factor which has been postulated to contribute to either acquisition or progression of Covid-19 is Vitamin D deficiency (VDD). ${ }^{9}$

Since the onset of the Covid-19 pandemic, the role of VDD has been a topic of intense research. ${ }^{10}$ Several studies have reported low serum levels in patients with Covid-19, especially those with severe disease, and in those who died of Covid-19. ${ }^{10}$ The recent meta-analysis also concluded that patients with VDD had an increased risk of developing the severe disease but not a fatal outcome. ${ }^{10}$ The studies conducted on the association between VDD and Covid-19 show a large degree of heterogeneity due to the differences in enrolment criteria of patients (age, body mass index, ethnicity, comorbidities), the country of residence, and the criteria used to define the severity of Covid- $19 .{ }^{10}$ Another similar meta-analysis concluded that the evidence for VDD's association with ICU admission, inflammation, hospitalization, and pulmonary involvement in Covid-19, is still inconsistent and insufficient. ${ }^{11}$ Furthermore, the impact of VDD on other outcome factors such as length of hospitalization and prognosis remains uncertain. ${ }^{12}$ More research is thus warranted to formulate concrete recommendations regarding VDD and Covid-19.

To guide further research, an assessment of the research conducted so far is essential. It helps in identifying the research gaps and the hotspots that the researchers need to focus on further. Such an assessment of previous research on any topic is often achieved through bibliometric studies. ${ }^{13,14}$ The bibliometric studies also help identify major research contributors such as leading authors, organizations, and countries that facilitate more meaningful collaborations. ${ }^{15}$ The previous bibliometric studies on Covid-19 did not evaluate the effects of VDD separately. ${ }^{16,17}$ Furthermore, the mapping studies on worldwide research on vitamin $\mathrm{D}$ were conducted prior to the Covid-19 pandemic. ${ }^{18-20}$ Thus, there is no bibliometric

This is an open access article distributed under the terms of the Creative Commons Attribution-NonCommercial-ShareAlike 4.0 License, which allows others to remix, tweak, and build upon the work non-commercially, as long as the author is credited and the new creations are licensed under the identical terms. 
assessment of VDD research in relation to the Covid-19 pandemic available in the literature so far. We, therefore, planned to provide a comprehensive bibliometric analysis of published research on VDD concerning Covid-19.

\section{MATERIALS AND METHODS}

We identified, retrieved, and downloaded publications on the theme "Covid-19 \& VDD" from the Scopus database (www.scopus.com). The approach used for the search was similar to our previous bibliometric studies. ${ }^{21-23}$ Two sets of keywords, "Covid-19" and "vitamin D deficiency," were used in field tags, "Keyword" or "Title" (Article Title), and the search was then limited to the 2020-2021 period. The complete search string is shown below:

(“Covid 19” OR "2019 novel coronavirus" OR "coronavirus 2019” OR "coronavirus disease 2019" OR "2019-novel CoV” OR "2019 ncov" OR covid 2019 OR covid19 OR "corona virus 2019” OR ncov-2019 OR ncov2019 OR "nCoV 2019" OR 2019-ncov OR covid-19 OR "Severe acute respiratory syndrome coronavirus 2" OR "SARS-CoV-2") OR KEY ("Covid 19” OR "2019 novel coronavirus" OR "coronavirus 2019” OR "coronavirus disease 2019" OR "2019-novel CoV” OR "2019 ncov" OR covid 2019 OR covid19 OR “corona virus 2019” OR ncov-2019 OR ncov2019 OR "nCoV 2019” OR 2019-ncov OR covid-19 OR "Severe acute respiratory syndrome coronavirus 2" OR “SARS-CoV-2") and Key' (Vitamin D deficiency).

The records obtained were analyzed using various bibliometric tools provided in the Scopus database. The quantitative characteristics were tabulated. The quality of publications was assessed using several quality indicators such as citations per publication (CPP), relative citation index (RCI), and Hirsch index (HI). The VOSviewer (version 1.6.14) software was used to examine the keywords clusters and collaborations networks of authors and institutions. The number of citations received by publications was counted up to August 8, 2021. Publications with more than 50 citations were labeled highly-cited publications (HCPs).

\section{RESULTS}

\section{Overall output and profile of publications}

The total number of publications was 435; these accumulated 5664 citations, averaging 13.0 CPP. The funded publications (88, 20.2\%) received marginally higher citations (average CPP 14.8, total 1309). The National Institute of Health, USA (18 papers), US Department of Health and Human Services (12 papers), and National Institute for Health Research (9 papers) were the leading funding agencies. The type of publications were original articles, reviews, and letters (42.9\%, 25.2\%, and $20.0 \%)$, editorials and notes $(6.4 \%$ and $4.3 \%)$, book chapters, conference paper and short survey $(0.4 \%, 0.2 \%$, and $0.2 \%)$.

\section{Significant keywords}

Forty-four keywords that indicate research trends on the VDD-Covid-19 theme were identified from the literature (Figure 1).

\section{Research focus}

Studies focused on risk factors accounted for the largest share of publications (29.6\%), followed by epidemiology (27.3\%), complications (26.4\%), clinical spectrum (24.8\%), and pathophysiology (17.2\%). Treatment aspects were less studied (14.0\%). Studies on pathophysiology received the highest (CPP 21.9) and complications the least (CPP 14.0) number of citations.

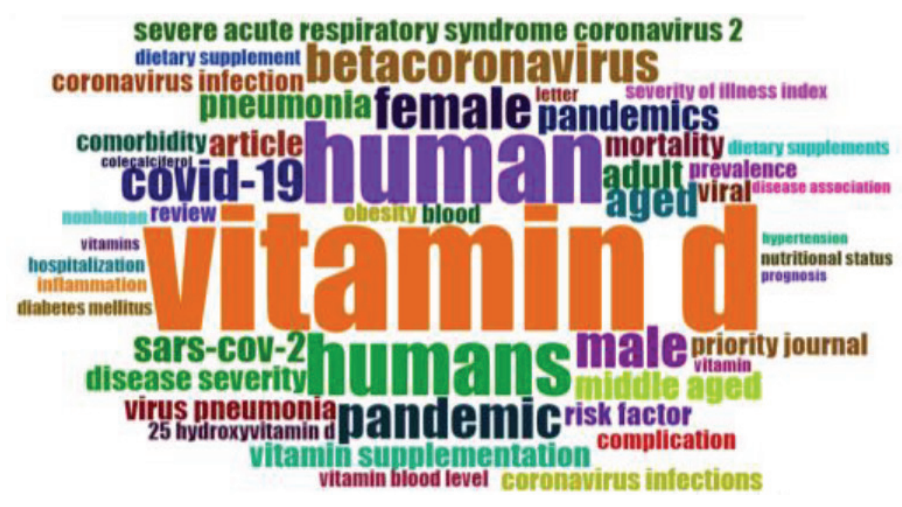

Figure 1: Word cloud based on author keywords and KeyWord Plus. The significance of the tags is according to the text dimension.

Table 1: The most productive countries in research on Covid-19 related vitamin $D$ deficiency.

\begin{tabular}{clcccccccc}
\hline S. no. & Country & TP & TC & CPP & HI & ICP & \%ICP & $\%$ TP & RCI \\
\hline 1 & USA $^{*}$ & 80 & 1683 & $21.0^{*}$ & 17 & 34 & 42.5 & 18.3 & $1.6^{*}$ \\
2 & Italy & 72 & 877 & 12.1 & 14 & 20 & 27.7 & 16.5 & 0.9 \\
3 & UK $^{*}$ & 67 & 1381 & $20.6^{*}$ & 16 & 33 & 49.2 & 15.4 & $1.5^{*}$ \\
4 & India & 33 & 360 & 10.9 & 7 & 8 & 24.2 & 7.5 & 0.8 \\
5 & Iran & 25 & 188 & 7.5 & 8 & 5 & 20.0 & 5.7 & 0.5 \\
6 & Turkey & 21 & 136 & 6.4 & 6 & 4 & 19.0 & 4.8 & 0.5 \\
7 & China & 17 & 198 & 11.6 & 8 & 6 & 35.2 & 3.9 & 0.8 \\
8 & Ireland & 16 & 363 & $22.6^{*}$ & 7 & 10 & 62.5 & 3.6 & $1.7^{*}$ \\
9 & Belgium & 15 & 110 & 7.3 & 5 & 5 & 33.3 & 3.4 & 0.5 \\
10 & Australia & 13 & 100 & 7.6 & 5 & 10 & 76.9 & 2.9 & 0.5 \\
& Total & 359 & 5396 & 15.0 & 9.3 & 135 & 37.6 & 82.5 & 1.1 \\
\hline
\end{tabular}

"more impactful countries

Abbreviations: $\mathrm{TP}=$ Total papers; $\mathrm{TC}=$ Total citations; $\mathrm{CPP}=\mathrm{Citations}$ per paper; $\mathrm{HI}=\mathrm{H}$-index; $\mathrm{ICP}=$ International collaborative papers; $\mathrm{RCI}=$ Relative citation index.

\section{Studied patient populations by age group}

The relative proportion of studies on adults, elderly, middle-aged, children, and adolescents was $24.1 \%, 21.6 \%, 17.7 \%$, children $6.4 \%$ and $3.9 \%$, respectively. Publications on the middle-aged population registered the highest, whereas those on children received the lowest CPP (20.9 versus 12.7)

\section{Top countries by productivity and impact}

The participation of 74 countries in research was unequal; 53 contributed 1-5 papers each, nine countries 6-10 papers each, nine countries 11-50 papers each, and three contributed $67-88$ publications. The top 10 countries contributed $82.5 \%$ of publications and $95.2 \%$ citations. Only three out of the top 10 countries registered higher CPP and RCI than their group average of 15.0 and 1.1 and were more impactful than others (Table 1). Substantial collaboration was noted between the top productive countries, with the UK, USA, and Italy leading others in the international collaborations (Figure 2).

\section{Leading organizations}

The contribution of 254 organizations was as follows: 239 contributed 1-5 papers each, 11 contributed 6-10 papers each, and four organizations 11-13 papers each. The top 15 organizations contributed almost one-third 


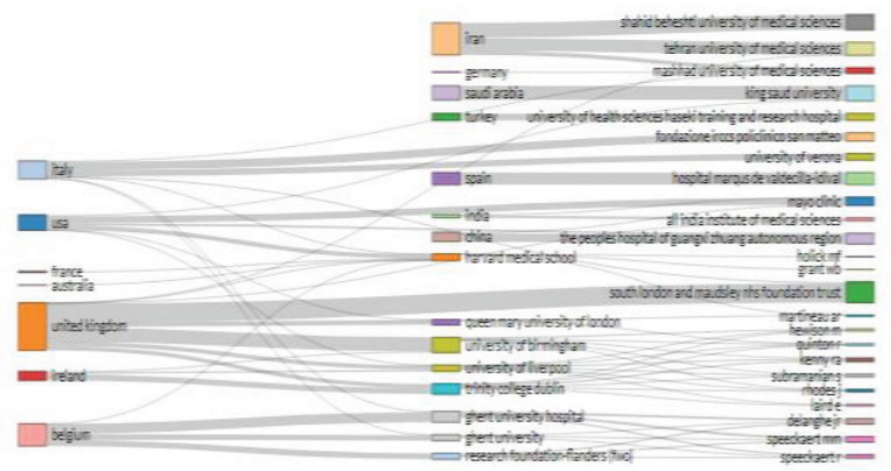

Figure 2: A three-fields plot of countries, organizations and authors showing their collaboration links. The size of the nodes and the width of the connecting lines is proportional to the significance of collaboration.

to the publication $(135,31.0 \%)$ and citation $(1777,31.3 \%)$ output. The productivity of eight organizations was above the group average of 9.0, whereas six registered CPP and RCI above their group average of 13.1 and 1.0, respectively (Table 2). Figure 3 shows the inter-organization collaborations in research.

\section{Most prolific and influential authors}

The contributions from 383 authors who participated in the research were unequal; respectively, 376 and 7 contributed 1-5 and 6-9 publications each. The top 15 authors contributed 92 (21.1\%) publications and 2010 (35.4\%) citations: six contributed a higher number of publications than their group average of 6.13 , whereas ten registered CPP and RCI above their group average 21.8 and 1.6, respectively. Table 3 shows the profiles of leading authors in productivity and impact. Figure 4 depicts the collaboration networks of authors.

\section{Top journals}

Of the 101 journals that participated in the research, 89 published 1-5 papers each, 11 contributed 6-10 papers, and one journal published 30 papers. The top 15 journals published $27.8 \%$ of the research on the current theme. The ten most productive and the most impactful journals are listed in Table 4.

\section{The highly-cited publications}

Only $28(6.4 \%)$ publications were HCPs receiving an average CPP of 113.6, and total citations 3181. The leading HCP contributors (2-8 publications) were the UK, the USA, Ireland, Italy, India, and Russia. Sixteen HCPs are published as original articles, eight as reviews, and two each as letters and notes. Eighteen HCPs were collaborative; 11 national and seven international collaborative. The top journals that published HCPs were Nutrients, Lancet Diabetology \& Endocrinology, and Irish Medical Journal, with 4, 2, and 2 papers.

\section{DISCUSSION}

Vitamin D deficiency is widely prevalent worldwide. ${ }^{24}$ Its association has been documented to either predispose or alter the course of several infective and autoimmune conditions such as respiratory and systemic infections, type 1 diabetes, systemic lupus erythematosus, systemic sclerosis, etc., probably due to the lack of immunomodulatory effects of vitamin D. ${ }^{25-29}$ VDD also affects several outcome parameters in hospitalized patients. ${ }^{29,30}$ Its role in the disease severity and progression and the possibility of amelioration were suggested during the initial phase of the Covid-19 epidemic. ${ }^{9}$ The recent meta-analyses of several studies also
Table 2: The most productive and the most influential organizations in Covid-19-related vitamin $D$ deficiency research.

\begin{tabular}{|c|c|c|c|c|c|c|c|c|}
\hline S.no. & Organization & TP & TC & CPP & $\mathrm{HI}$ & ICP & $\%$ ICP & $\mathrm{RCl}$ \\
\hline \multicolumn{9}{|c|}{ Most productive organizations } \\
\hline 1 & $\begin{array}{l}\text { Trinity College, Dublin, } \\
\text { Ireland }\end{array}$ & 13 & 348 & 26.7 & 6 & 10 & 46.1 & 2.0 \\
\hline 2 & Harvard Medical School, USA & 11 & 84 & 7.6 & 5 & 4 & 45.4 & 0.5 \\
\hline 3 & University of Liverpool, U.K. & 11 & 284 & 25.8 & 6 & 9 & 54.5 & 1.9 \\
\hline 4 & $\begin{array}{l}\text { University Hospital of Ghent, } \\
\text { Belgium }\end{array}$ & 11 & 30 & 2.7 & 3 & 2 & 27.2 & 0.2 \\
\hline 5 & University of Brigham, U.K & 10 & 53 & 5.3 & 5 & 5 & 50.0 & 0.4 \\
\hline 6 & $\begin{array}{l}\text { Tehran University of Medical } \\
\text { Sciences, Iran }\end{array}$ & 10 & 54 & 5.4 & 4 & 2 & 40.0 & 0.4 \\
\hline 7 & $\begin{array}{l}\text { Sapienza University of Rome, } \\
\text { Italy }\end{array}$ & 10 & 89 & 8.9 & 5 & 4 & 50.0 & 0.6 \\
\hline 8 & University of Ghent, Belgium & 10 & 46 & 4.6 & 3 & 2 & 30.0 & 0.3 \\
\hline 9 & $\begin{array}{l}\text { Research Foundation } \\
\text { Flanders, Belgium }\end{array}$ & 9 & 26 & 2.8 & 2 & 0 & 22.2 & 0.2 \\
\hline 10 & $\begin{array}{l}\text { Shahid Beheshti University of } \\
\text { Medical Sciences, Iran }\end{array}$ & 8 & 55 & 6.8 & 4 & 0 & 50.0 & 0.5 \\
\hline \multicolumn{9}{|c|}{ Most impactful organizations } \\
\hline 1 & St James's Hospital, Ireland & 6 & 232 & 38.6 & 3 & 4 & 50.0 & 2.9 \\
\hline 2 & $\begin{array}{l}\text { University Hospital Brigham } \\
\text { NHS Foundation Trust, U.K. }\end{array}$ & 7 & 268 & 38.2 & 5 & 2 & 71.4 & 2.9 \\
\hline 3 & $\begin{array}{l}\text { Trinity College, Dublin, } \\
\text { Ireland }\end{array}$ & 13 & 348 & 26.7 & 6 & 10 & 46.1 & 2.0 \\
\hline 4 & University of Liverpool, U.K. & 11 & 284 & 25.8 & 6 & 9 & 54.5 & 1.9 \\
\hline 5 & $\begin{array}{l}\text { Queen Mary University of } \\
\text { London, U.K. }\end{array}$ & 6 & 153 & 25.5 & 4 & 2 & 66.6 & 1.9 \\
\hline 6 & $\begin{array}{l}\text { Sapienza University of Rome, } \\
\text { Italy }\end{array}$ & 10 & 89 & 8.9 & 5 & 4 & 50.0 & 0.6 \\
\hline 7 & Harvard Medical School, USA & 11 & 84 & 7.6 & 5 & 4 & 45.4 & 0.5 \\
\hline 8 & $\begin{array}{l}\text { Shahid Beheshti University of } \\
\text { Medical Sciences, Iran }\end{array}$ & 8 & 55 & 6.8 & 4 & 0 & 50.0 & 0.5 \\
\hline 9 & University of Brigham, U.K & 10 & 53 & 5.3 & 5 & 5 & 50.0 & 0.4 \\
\hline 10 & $\begin{array}{l}\text { Tehran University of Medical } \\
\text { Sciences, Iran }\end{array}$ & 10 & 54 & 5.4 & 4 & 2 & 40.0 & 0.4 \\
\hline
\end{tabular}

Abbreviations: $\mathrm{TP}=$ Total papers; $\mathrm{TC}=$ Total citations; $\mathrm{CPP}=\mathrm{Citations}$ per paper; $\mathrm{HI}=$ Hirsch Index; ICP=International collaborative papers; $\mathrm{RCI}=$ Relative citation index

point towards the association of VDD with the severity and outcome of Covid-19 in hospitalized patients. ${ }^{10,11}$ However, despite extensive research conducted on VDD in Covid-19 patients, the exact prognostic value of VDD in these patients remains uncertain. ${ }^{12}$ Our bibliometric analysis also indicates the presence of some research gaps in the Covid-19-related VDD research, which are discussed below.

A significant finding of our study was that Covid-related VDD research was mainly concentrated in high-income countries. Almost $50 \%$ of global publications and $70 \%$ of citations were attributable to the USA, Italy, and the UK. This observation is similar to the previous scientometric studies that show higher productivity and quality of research in the high-income countries belonging to North American and Western European continents. ${ }^{31,32}$ The better quality of research was probably due to the availability of funding; the major funding agencies were located in these regions only. The funded publications had received better citations as compared to non-funded publications, which is an established fact. ${ }^{33}$ In contrast, the non-availability of funds for research in low-income 
Table 3: Profiles of leading authors in research on vitamin D deficiency-related Covid-19 research.

\begin{tabular}{|c|c|c|c|c|c|c|c|c|c|}
\hline S.no. & Author & Affiliation & TP & TC & CPP & $\mathrm{HI}$ & ICP & \%ICP & $\mathrm{RCl}$ \\
\hline \multicolumn{10}{|c|}{ Most productive authors } \\
\hline 1 & J.R.Delanghe & University of Ghent, Belgium & 9 & 26 & 2.8 & 2 & 0 & 0.0 & 0.2 \\
\hline 2 & R.A.Kenny & Trinity College, Dublin, Ireland & 9 & 261 & 29.0 & 5 & 8 & 88.9 & 2.2 \\
\hline 3 & M.M. Speeckaert & University Hospital of Ghent, Belgium & 9 & 26 & 2.8 & 2 & 0 & 0.0 & 0.2 \\
\hline 4 & A.Glustina & Universita Vita-Salute San Raffaele, Italy & 7 & 56 & 8.0 & 5 & 2 & 28.6 & 0.6 \\
\hline 5 & E.Laird & Trinity College, Dublin, Ireland & 7 & 245 & 35.0 & 4 & 6 & 85.7 & 2.6 \\
\hline 6 & S.Subramanian & Trinity College, Dublin, Ireland & 7 & 187 & 26.7 & 4 & 6 & 85.7 & 2.0 \\
\hline 7 & M.F.Holick & Boston University School of Medicine, USA & 6 & 106 & 17.6 & 4 & 0 & 0.0 & 1.3 \\
\hline 8 & W.B.Grant & Nutrition \& Health Research Center, USA & 5 & 678 & 135.6 & 3 & 2 & 40.0 & 10.4 \\
\hline 9 & M.Hewison & University of Brigham, U.K. & 5 & 23 & 4.6 & 2 & 3 & 60.0 & 0.3 \\
\hline 10 & A.R.Martin & Bart \& The London School of Medicine \& Dentistry, UK & 5 & 140 & 28.0 & 3 & 1 & 20.0 & 2.1 \\
\hline \multicolumn{10}{|c|}{ Most impactful authors } \\
\hline 1 & W.B.Grant & Nutrition \& Health Research Center, USA & 5 & 678 & 135.6 & 3 & 2 & 40.0 & 10.4 \\
\hline 2 & E.Laird & Trinity College, Dublin, Ireland & 7 & 245 & 35.0 & 4 & 6 & 85.7 & 2.6 \\
\hline 3 & R.A.Kenny & Trinity College, Dublin, Ireland & 9 & 261 & 29.0 & 5 & 8 & 88.9 & 2.2 \\
\hline 4 & A.R.Martin & Bart \& The London School of Medicine \& Dentistry, UK. & 5 & 140 & 28.0 & 3 & 1 & 20.0 & 2.1 \\
\hline 5 & S.Subramanian & Trinity College, Dublin, Ireland & 7 & 187 & 26.7 & 4 & 6 & 85.7 & 2.0 \\
\hline 6 & J.Rhodes & University of Liverpool, U.K. & 5 & 91 & 18.2 & 2 & 5 & 100.0 & 1.4 \\
\hline 7 & G.Griffin & Trinity College, Dublin, Ireland & 4 & 72 & 18.0 & 2 & 4 & 100.0 & 1.3 \\
\hline 8 & M.F.Holick & Boston University School of Medicine, USA & 6 & 106 & 17.6 & 4 & 0 & 0.0 & 1.3 \\
\hline 9 & R.Quinton & Newcastle University, UK & 5 & 81 & 16.2 & 3 & 3 & 60.0 & 1.2 \\
\hline 10 & A.Glustina & Universita Vita-Salute San Raffaele, Italy & 7 & 56 & 8.0 & 5 & 2 & 28.6 & 0.6 \\
\hline
\end{tabular}

Abbreviations: $\mathrm{TP}=$ Total papers; $\mathrm{TC}=$ Total citations; $\mathrm{HI}=$ Hirsch Index; $\mathrm{CPP}=$ Citations per paper; $\mathrm{ICP}=$ International collaborative papers; $\mathrm{RCI}=\mathrm{Relative}$ citation index.

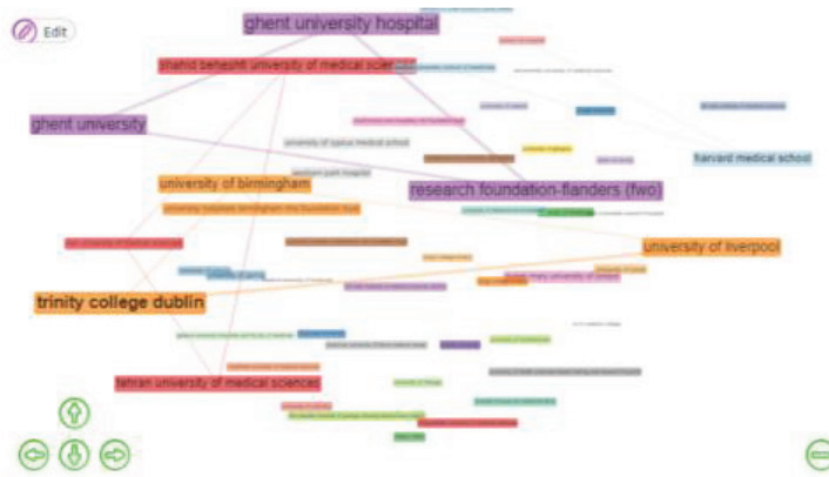

Figure 3: Collaboration network of organizations researching vitamin $D$ deficiency in relation to the Covid-19. The width of the linking lines and the distance between organizations reflect the degree of collaborative relationships.

countries often leads to a low quantity and quality of research..$^{34}$ Another factor that probably contributed to a better quality of research in highincome countries was a higher degree of collaboration in research. Organizations and researchers located in high-income countries showed better collaborative networking as compared to those in low-income countries. Collaborative research improves the quality and leads to the development of better future management strategies. ${ }^{35}$ In this context, it is important to foster collaboration in Covid-related VDD research between high- and low-income countries for improving the outcomes of Covid-19 patients worldwide, similar to research strengthening initiatives in other diseases. ${ }^{36}$

Another notable observation was the small number of studies on the treatment-related aspects of VDD in Covid-19. As vitamin D status has been shown to influence the length of hospital stay and prognosis in hospitalized Covid-19 patients, it is reasonable to assume that treatment of VDD at admission may improve outcomes. ${ }^{12}$ Thus, the role of large doses of cholecalciferol supplementation in the community and at hospitalization, as suggested by Grant WB et al., needs to be explored through extensive multicentric and international collaborative research. ${ }^{37} \mathrm{We}$ also noted that studies on the childhood population were very few, constituting about $10 \%$ of all publications. This is understandable as most children had a mild disease during the initial wave of Covid-19. ${ }^{38}$ The subsequent waves of Covid-19 are expected to affect more children due to non-vaccination, and optimal strategies are currently being defined for mitigating effects on children. ${ }^{39} \mathrm{~A}$ role of several therapeutic modalities, including vitamins, is being worked out. ${ }^{40}$ Researchers have suggested conducting high-quality randomized controlled trials to evaluate the role of supplements, including vitamin $\mathrm{D}$, in treating or preventing Covid-19 in children. ${ }^{40}$ Children, therefore, should gain priority in future research on Covid-related VDD.

A limitation of our study was using a single database for the bibliometric assessment, similar to our previous bibliometric studies. ${ }^{21-23}$ Single database studies are likely to miss some publication and citation data. However, it is also true that most bibliometric studies are based on a single database, with Scopus regarded as the most authoritative of all medical databases due to its wider content coverage, accuracy, and citation analysis tools. ${ }^{41}$ 
Table 4: Most active and influential journals in research on Covid-19-related vitamin D deficiency.

\begin{tabular}{|c|c|c|c|c|}
\hline S.no. & Journal & TP & TC & CPP \\
\hline \multicolumn{5}{|c|}{ Most productive journals } \\
\hline 1 & Nutrients & 30 & 1257 & 41.9 \\
\hline 2 & Journal of Medical Virology & 9 & 57 & 6.3 \\
\hline 3 & Endocrine & 8 & 67 & 8.3 \\
\hline 4 & Irish Medical Journal & 8 & 180 & 22.5 \\
\hline 5 & Alimentary Pharmacology \& Therapeutics & 7 & 223 & 31.8 \\
\hline 6 & $\begin{array}{l}\text { Clinical Medicine Journal of the Royal College of } \\
\text { Physicians of London }\end{array}$ & 7 & 78 & 11.1 \\
\hline 7 & Aging Clinical \& Experimental Research & 6 & 300 & 50.0 \\
\hline 8 & Clinical Nutrition Espen & 6 & 14 & 2.3 \\
\hline 9 & European Journal of Nutrition & 6 & 33 & 5.5 \\
\hline 10 & Italian Journal of Medicine & 6 & 1 & 0.1 \\
\hline \multicolumn{5}{|c|}{ Most impactful journals } \\
\hline 1 & Aging Clinical \& Experimental Research & 6 & 300 & 50.0 \\
\hline 2 & $\begin{array}{l}\text { Diabetes \& Metabolic Syndrome: Clinical } \\
\text { Research \& Review }\end{array}$ & 5 & 232 & 46.4 \\
\hline 3 & Nutrients & 30 & 1257 & 41.9 \\
\hline 4 & Alimentary Pharmacology \& Therapeutics & 7 & 223 & 31.8 \\
\hline 5 & Irish Medical Journal & 8 & 180 & 22.5 \\
\hline 6 & Metabolism. Clinical \& Experimental & 6 & 131 & 21.8 \\
\hline 7 & $\begin{array}{l}\text { Clinical Medicine Journal of the Royal College of } \\
\text { Physicians of London }\end{array}$ & 7 & 78 & 11.1 \\
\hline 8 & Journal of the American College of Nutrition & 6 & 65 & 10.8 \\
\hline 9 & $\begin{array}{l}\text { European Review For Medicinal \& } \\
\text { Pharmacological Science }\end{array}$ & 5 & 47 & 9.4 \\
\hline 10 & Endocrine & 8 & 67 & 8.3 \\
\hline
\end{tabular}

Abbreviations: $\mathrm{TP}=$ Total papers; $\mathrm{TC}=$ Total citations; $\mathrm{CPP}=$ Citations per paper

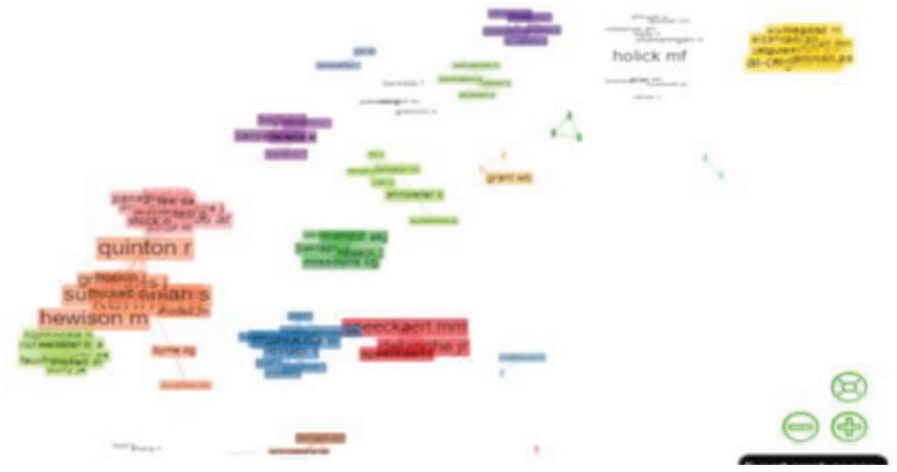

Figure 4: Collaboration network of authors involved in research on vitamin $D$ deficiency concerning the Covid-19.

Furthermore, searching all databases simultaneously is quite cumbersome due to a lack of uniformity in the available analytical provisions. ${ }^{42}$

\section{CONCLUSION}

Most of the research on VDD in relation to the Covid-19 has been conducted in high-income countries. There is a need to focus on treatment-related aspects, involvement of childhood populations, and increasing collaboration between high- and low-income countries to better manage VDD concerning Covid-19.

\section{CONFLICT OF INTEREST}

The authors declare no conflict of interest.

\section{REFERENCES}

1. Kumar R, Bharti N, Kumar S, Prakash G. Multidimensional impact of Covid-19 pandemic in India-Challenges and future direction. J Family Med Prim Care. 2020;9(12):5892-5. doi: 10.4103/jfmpc.jfmpc_1625_20, PMID 33681014.

2. Dayal D, Gupta S, Raithatha D, Jayashree M. Missing during Covid-19 lockdown: children with onset of type 1 diabetes. Acta Paediatr. 2020;109(10):2144-6. doi: 10.1111/apa.15443, PMID 32575149.

3. Dayal D. We urgently need guidelines for managing Covid-19 in children with comorbidities. Acta Paediatr. 2020;109(7):1497-8. doi: 10.1111/apa.15304, PMID 32279351.

4. Dayal D, Yadav A. Covid-19: Considerations for children and adolescents with diabetes. J Diabetol. 2020;11(3):126-30. doi: 10.4103/JOD.JOD_40_20.

5. Park SC, Won SY, Kim NH, Choi H, Youk TM, Lee HJ, Jeon HH. Risk factors for severe acute respiratory syndrome coronavirus 2 (SARS-CoV-2) infections: a nationwide population-based study. Ann Transl Med. 2021:9(3):211. doi: 10.21037/atm-20-5958, PMID 33708838

6. Pınarlık F, Genç Z, Kapmaz M, Tekin S, Ergönül Ö. Risk groups for SARS-CoV-2 infection among healthcare workers: community versus hospital transmission. Infect Dis Rep. 2021;13(3):724-9. doi: 10.3390/idr13030067, PMID 34449648

7. Dayal D, Gupta S. Connecting BCG vaccination and Covid-19: additional data. MedRxiv. 2020. doi: 10.1101/2020.04.07.20053272 [preprint]

8. Basak P, Sachdeva N, Dayal D. Can BCG vaccine protect against Covid-19 via trained immunity and tolerogenesis? BioEssays. 2021:43(3):e2000200. doi: 10.1002/bies.202000200, PMID 33169410.

9. Dayal D. Possible role of vitamin D supplementation in coronavirus disease 2019. Int J Sci Rep. 2020;6(9):376-8. doi: 10.18203/issn.2454-2156.IntJSciRep20203554.

10. Crafa A, Cannarella R, Condorelli RA, Mongioì LM, Barbagallo F, Aversa A, La Vignera S, Calogero AE. Influence of 25-hydroxy-cholecalciferol levels on SARSCoV-2 infection and Covid-19 severity: A systematic review and meta-analysis. EClinicalmedicine. 2021;37:100967. doi: 10.1016/j.eclinm.2021.100967.

11. Kazemi A, Mohammadi V, Aghababaee SK, Golzarand M, Clark CCT, Babajafari S Association of vitamin D status with SARS-CoV-2 infection or Covid-19 severity: A systematic review and meta-analysis. Adv Nutr. 2021 Mar 5:nmab012. doi 10.1093/advances/nmab012 [Epub ahead of print]. PMID 33751020.

12. Reis BZ, Fernandes AL, Sales LP, Santos MD, Dos Santos CC, Pinto AJ et al. Influence of vitamin D status on hospital length of stay and prognosis in hospitalized patients with moderate to severe Covid-19: a multicenter prospective cohort study. Am J Clin Nutr. 2021;114(2):598-604. doi: 10.1093/ajcn/nqab151, PMID 34020451.

13. Cooper ID. Bibliometrics basics. J Med Libr Assoc. 2015;103(4):217-8. doi: 10.3163/1536-5050.103.4.013, PMID 26512226.

14. Dayal D, Gupta BM. Pediatric hyperthyroidism research: A scientometric assessment of global publications during 1990-2019. Thyroid Res Pract. 2020;17(3):134-40. doi: 10.4103/trp.trp_67_20.

15. Morán-Mariños C, Toro-Huamanchumo CJ, Pacheco-Mendoza J. Bibliometric profile and collaborative networks in scientific research on systemic lupus erythematosus in Latin America, 1982-2018. Reumatol Clin (Engl Ed) 2021;17(7):404-7. doi: 10.1016/j.reumae.2020.01.004, PMID 34301384

16. Gupta B, Dhawan S, Mueen Ahmed K, Mamdapur GM. Global Research on Covid-19 Disease: A Scientific Assessment of Publications during 2020-21. IJMEDPH. 2021;11(2):76-84. doi: 10.5530/ijmedph.2021.2.14

17. Klingelhöfer $D$, Braun $M$, Brüggmann $D$, Groneberg DA. The Pandemic Year 2020: World Map of Coronavirus Research. J Med Internet Res. $2021 \mathrm{Ju}$ 8:23(9):e30692. doi: 10.2196/30692 [Epub ahead of print]. PMID 34346891.

18. Gupta R, Gupta BM, Baidwani K, Kaur J. A Scientometric assessment of Indian publications on vitamin D deficiency during 2006-15. J Young Pharm. 2016;8(4):302-9. doi: 10.5530/jyp.2016.4.3

19. Brüggmann $D$, Alafi $A$, Jaque J, Klingelhöfer $D$, Bendels $M H$, Ohlendorf $D$, Quarcoo D, Louwen F, Ingles SA, Wanke EM, Groneberg DA. World-wide research architecture of vitamin $D$ research: density-equalizing mapping studies and socio-economic analysis. Nutr J. 2018;17(1):3. doi: 10.1186/s12937-018-0313-6, PMID 29306332

20. Yang A, Lv Q, Chen F, Wang D, Liu Y, Shi W. Identification of recent trends in research on vitamin D: A quantitative and co-word analysis. Med Sci Monit. 2019:25:643-55. doi: 10.12659/MSM.913026, PMID 30668558

21. Gupta BM, Dayal D. Pediatric type 1 diabetes research in the 21 st century: a scientometric review. Pediatr Endocrinol Diabetes Metab. 2020:26(3):132-9. doi: 10.5114/pedm.2020.98165, PMID 32901470

22. Dayal D, Gupta BM, Gupta S. Quantitative and qualitative assessment of Indian research yield in type 1 diabetes during 1996-2019. J Diabetol. 2021;12(1):28-35 doi:10.4103/jod.jod_46_20

23. Gupta BM, Pal R, Rohilla L, Dayal D. Bibliometric analysis of diabetes research in relation to the Covid-19 pandemic. J Diabetol. 2021;12(3):350-6.doi:10.4103/ 
JOD.JOD_30_21.

24. Dayal D, Jayaraman D. Vitamin D deficiency: dealing with the current epidemic. In: Singhi S, Mathew J, editors. Current pediatrics practice. 3rd ed. New Delhi, India: Peepee Publishers; 2015. p. 69-75.

25. Vaghari-Tabari M, Mohammadzadeh I, Qujeq D, Majidinia M, Alemi F, Younesi S, Mahmoodpoor A, Maleki M, Yousefi B, Asemi Z. Vitamin D in respiratory vira infections: a key immune modulator? Crit Rev Food Sci Nutr. 2021 Sep 2:1-16. doi: 10.1080/10408398.2021.1972407 [Epub ahead of print]. PMID 34470511.

26. Borkar VV, Devidayal VS, Verma S, Bhalla AK. Low levels of vitamin D in North Indian children with newly diagnosed type 1 diabetes. Pediatr Diabetes. 2010;11(5):345-50. doi: 10.1111/j.1399-5448.2009.00589.x, PMID 19906128.

27. Dayal D, Jayashree M. Vitamin $D$ levels in newly detected Type 2 diabetes. Indian J Endocrinol Metab. 2015;19(2):308. doi: 10.4103/2230-8210.149333, PMID 25729703.

28. Dupuis ML, Pagano MT, Pierdominici M, Ortona $E$. The role of vitamin $D$ in autoimmune diseases: could sex make the difference? Biol Sex Differ. 2021;12(1):12. doi: 10.1186/s13293-021-00358-3, PMID 33436077.

29. Ponnarmeni S, Kumar Angurana S, Singhi S, Bansal A, Dayal D, Kaur R, Patial A Verma Attri S. Vitamin D deficiency in critically ill children with sepsis. Paediatr Int Child Health. 2016;36(1):15-21. doi: 10.1179/2046905515Y.0000000042, PMID 26120004.

30. Dayal D, Kumar S, Sachdeva N, Kumar R, Singh M, Singhi S. Fall in vitamin D levels during hospitalization in children. Int J Pediatr. 2014;2014:291856. doi: 10.1155/2014/291856

31. Dayal D, Gupta BM, Gupta A. Thyroid disorders in children and adolescents: systematic mapping of global research over the past three decades. Thyroid Res Pract. 2021;18(1):23-30. doi: 10.4103/trp.trp_5_21.

32. Gupta BM, Mamdapur GM, Gupta S, Rohilla L, Dayal D. Global mucormycosis research: A bibliometric assessment based on Scopus database (1998-2021). J Young Pharm. 2021;13(4).

33. Fradkin JE, Wallace JA, Akolkar B, Rodgers GP. Type 1 diabetes--reaping the rewards of a targeted research investment. Diabetes. 2016;65(2):307-13. doi: 10.2337/db15-1030, PMID 26798117.

34. Lakhotia SC. Research fund crunch, real or created, is hitting India's Academia on the Wrong Side. Proc Indian Natl Sci Acad. 2018;98(3):545-7. doi: 10.16943/ ptinsa/2018/49475.

35. Vaudano E. Research collaborations and quality in research: foes or friends? Handb Exp Pharmacol. 2020;257:383-98. doi: 10.1007/164_2019_293, PMID 31628602.

36. Haregu TN, Byrnes A, Singh K, Sathish T, Pasricha N, Wickramasinghe K, et al. A scoping review of non-communicable disease research capacity strengthening initiatives in low and middle-income countries. Glob Health Res Policy. 2019;4:31. doi: 10.1186/s41256-019-0123-1, PMID 31799408.

37. Grant WB, Lahore H, McDonnell SL, Baggerly CA, French CB, Aliano JL, et al. Evidence that vitamin $D$ supplementation could reduce risk of influenza and Covid-19 infections and deaths. Nutrients. 2020;12(4):988. doi: 10.3390/ nu12040988, PMID 32252338.

38. Ludvigsson JF. Systematic review of Covid-19 in children shows milder cases and a better prognosis than adults. Acta Paediatr. 2020;109(6):1088-95. doi: 10.1111/apa.15270, PMID 32202343

39. Panovska-Griffiths J, Kerr CC, Stuart RM, Mistry D, Klein DJ, Viner RM, et al Determining the optimal strategy for reopening schools, the impact of test and trace interventions, and the risk of occurrence of a second Covid-19 epidemic wave in the UK: a modelling study. Lancet Child Adolesc Health. 2020;4(11):817-27. doi: 10.1016/S2352-4642(20)30250-9, PMID 32758453.

40. Younis NK, Zareef RO, Fakhri G, Bitar F, Eid AH, Arabi M. Covid-19: potential therapeutics for pediatric patients. Pharmacol Rep. 2021 Aug 30. doi: 10.1007/ s43440-021-00316-1 [Epub ahead of print]. PMID 34458951.

41. Baas J, Schotten M, Plume A, Côté G, Karimi R. Scopus as a curated, highquality bibliometric data source for academic research in quantitative science studies. Quant Sci Stud. 2020;1(1):377-86. doi: 10.1162/qss_a_00019.

42. Kokol P, Vošner HB. Discrepancies among Scopus, Web of Science, and PubMed coverage of funding information in medical journal articles. J Med Libr Assoc. 2018;106(1):81-6. doi: 10.5195/jmla.2018.181, PMID 29339937.

Article History: Received: 27-08-2021; Revised: 21-09-2021; Accepted: 30-10-2021.

Cite this article: Dayal D, Gupta BM, Surulinathi M, Nanda P. Covid-19 and Vitamin D Deficiency: A Scientometric Assessment of Global Publications during 2020-21. J Young Pharm. 2021;13(3) Suppl:s89-s94. 